\title{
A Fictive Stress Model and Nonlinear Viscoelastic Behaviors in Metallic Glasses
}

\author{
H. S. Chen ${ }^{1}$, Hidemi Kato ${ }^{2}$ and Akihisa Inoue ${ }^{2}$ \\ ${ }^{1}$ Bell Laboratories, Lucent Technology, Murray Hill, New Jersey 07974, USA and Presently at Graduate School of \\ Materials Science, Chinese Culture University, Yang-Ming Shang, Taipei, Taiwan, ROC \\ ${ }^{2}$ Institute for Materials Research, Tohoku University, Sendai 980-8577, Japan
}

\begin{abstract}
Transition behaviors from linear to nonlinear viscoelasticity under constant strain-rate deformation near the glass transition have been investigated for Pd-and Zr-based alloy glasses. The transition occurs at critical strain-rate, and the steady-state viscosity may decrease by many orders of magnitude above the critical strain-rate. Concurrently with the transition, the growth of the stress shows a stress-overshoot; the stress increases initially attaining a maximum, then decreases and attains a steady-state flow. The transition between steady-state Newtonian and non-Newtonian flows can be analyzed by a stretched exponent relaxation function, and both the normalized viscosity and the flow stress can be represented by a master curve in terms of the product of the strain-rate and the Newtonian viscosity. These results imply that the occurrence of the transition from the Newtonian to non-Newtonian is explicitly determined by the flow stress. A model, based on the hypothesis of stressinduced structural relaxation and the concept of fictive stress for the nonlinear viscoelastic behaviors has been proposed. The model calculation has reproduced fairly well the experimental results of the Pd- and Zr-based glasses, in particular, the development of the stress-overshoot behavior. In addition, the model reveals a stress-overshoot and under-shoot oscillation at very high strain-rate. This oscillatory nonlinear behavior has been observed in many polymer solutions, and also the latest study in metallic glasses. The model calculations of other nonlinear viscoelastic behaviors, such as stress relaxation during stress growth after abrupt cessation of steady-state flow, and a stress regrowth after a brief interval of relaxation, are also presented.
\end{abstract}

(Received December 11, 2000; Accepted February 22, 2001)

Keywords: metallic glass, supercooled liquid, viscoelasticity, viscous flow, fictive stress

\section{Introduction}

A number of alloy systems, such as $\mathrm{Pd}-\mathrm{Ni}-\mathrm{P}, \mathrm{Pd}-\mathrm{Cu}-\mathrm{Si}$, and $\mathrm{Pt}-\mathrm{Ni}-\mathrm{P}$ have been known for sometimes as very easy glass formers. ${ }^{1)}$ Recently Ln-Al-TM, Zr-Al-TM, Hf-Al$\mathrm{TM}$, and Mg-TM- $\mathrm{Ln}$ have been found to form a glass easily. ${ }^{2)}$ Here TM stands for transition metals $\mathrm{Fe}, \mathrm{Co}, \mathrm{Ni}$, and $\mathrm{Cu}$. These alloys can be cast into a bulk glass form from a melt at cooling rates as low as $10 \mathrm{~K} / \mathrm{s}$, and the glasses show a wide supercooled liquid region before crystallization. The high stability and fluidity of these glass alloys opens the possibility of forming bulk materials of various shapes, at elevated temperatures with straightforward processes, such as casting, forging, extrusion and consolidation. The Newtonian viscosities, $\eta_{\mathrm{N}}$, near $T_{\mathrm{g}}$, obtained from creep measurements at a sufficiently low stress, have been reported for metallic glasses firstly for $\mathrm{Au}-\mathrm{Ge}-\mathrm{Si}^{3)}$ and $\mathrm{Pd}-\mathrm{Si}^{4}{ }^{4)}$ then for a number of alloy glasses. ${ }^{5-7)}$ The temperature dependence of $\eta_{\mathrm{N}}$ of many stable glasses has also been extracted from the rates of thermal transformations. ${ }^{8)}$ Over a broad temperature range in the region of the glass transition, the viscosity, $\eta_{\mathrm{N}}$, of metallic glasses as well as many non-metallic glasses increases rapidly in the range $10^{5}-10^{13} \mathrm{~Pa} \cdot \mathrm{s}$ and is described by the Vogel-FulcherTammann (VFT) expression, $\eta_{\mathrm{N}}=\eta_{0} \exp \left[Q /\left(T-T_{0}\right)\right]$, where $T_{0}$ is the VFT temperature. When the flow stress is sufficiently high, however, the viscosity of metallic glasses becomes non-Newtonian.

The viscosity of $\mathrm{Pd}_{40} \mathrm{Ni}_{10} \mathrm{Cu}_{30} \mathrm{P}_{20}$ and $\mathrm{Zr}_{55} \mathrm{Al}_{10} \mathrm{Ni}_{5} \mathrm{Cu}_{30}{ }^{9}, 10$ ) alloy glasses near $T_{\mathrm{g}}$ has been investigated recently as a function of temperature and strain rate under compression. The steady-state viscosity of glass at a given temperature remains constant at low strain rate, $\dot{\varepsilon}$, and decreases above a critical strain rate $\dot{\varepsilon}_{c}$, indicating Newtonian to non-Newtonian flow. The viscosity, $\eta$, may decrease by many orders of magni- tude. The growth of stress, $\sigma$, at strain rate $\dot{\varepsilon}<\dot{\varepsilon}_{\mathrm{c}}$ follows a linear viscoelastic behavior which predicts a monotonic increase of the asymptotic value $\sigma_{\infty}=3 \eta_{\mathrm{N}} \dot{\varepsilon}$. However if $\dot{\varepsilon}\left(>\dot{\varepsilon}_{\mathrm{c}}\right)$ is sufficiently high to create a non-Newtonian regime, it shows a stress-overshoot: $\sigma$ increases initially attaining a maximum, then decreases and attains a steady-state flow value, $\sigma_{\mathrm{f}}$. The stress-overshoot, a nonlinear viscoelastic behavior is commonly observed in polymers ${ }^{11)}$ and some inorganic glasses. ${ }^{12)}$ The critical strain-rate, $\dot{\varepsilon}_{\mathrm{c}}$, strongly depends on temperature, and inversely scales to Newtonian viscosity, $\eta_{\mathrm{N}}$. A master curve for a glass alloy in terms of the viscosity ratio, $\eta_{\mathrm{f}} / \eta_{\mathrm{N}}$, and the product, $\eta_{\mathrm{N}} \dot{\varepsilon}$, of the Newtonian viscosity and strain rate has been constructed. The flow stress, $\sigma_{\mathrm{f}}$, can be represented by a master curve in terms of the product, $\eta_{\mathrm{N}} \dot{\varepsilon}$. The flow stress, $\sigma_{\mathrm{f}}$, increases proportionally with strain rate in the Newtonian regime and tends to flatten out at a high strain rate in the non-Newtonian regime. A relaxation model is proposed and the master curves are fitted with a simple stress relaxation function of the form, $1-\exp \left[-\left(1 / t_{1} \dot{\gamma}\right)^{\beta}\right]$, where $t_{1}$ is a time constant, $\dot{\gamma}$ the shear rate and $\beta$ the KWW stretched exponent. The general feature of this nonlinear behavior of stress-overshoot can be understood quantitatively in terms of molecular theory ${ }^{13}$ ) in which non-Newtonian flow is attributed to the reduction in concentration of entanglement coupling with increasing rate. In the non-Newtonian regime, a stress-overshoot exists because initially the structural breakdown processes, governed by Newtonian flow, are much slower than the shear relaxation governing the steadystate viscosity. Recent computer simulations ${ }^{13,14)}$ of LennardJones glasses reveal that the shearing action changes the liquid directionality facilitating flow and reducing viscosity, and causes an overshoot in the stress versus strain curve in the non-Newtonian regime.

A general theory, regardless of differences in molecular structures among glassy polymers, inorganic glasses and 
atomic metallic glasses, is that there exists a steady-state flow structure of a liquid corresponding to a given strain rate and stress. Specifically, there exists a corresponding normalized viscosity, $\eta_{\mathrm{f}} / \eta_{\mathrm{N}}$, or relaxation time, $\lambda_{\mathrm{f}} / \lambda_{\mathrm{N}}$, to a given steadystate flow stress, $\sigma_{f}$, in a liquid. Here subscripts $f$ and $N$ stand for steady-state flow at constant strain rate (or a constant stress) and Newtonian flow, respectively. We hereby introduce an additional structural parameter, a fictive stress, $\sigma_{\mathrm{f}}$, analogous to fictive temperature, $T_{\mathrm{f}}$. In other words, we introduce relaxation time or the nonlinear dependence of relaxation time to change in the stress-induced structure. In this paper, we propose a model for nonlinear viscoelastic relaxation based on the hypothesis of stress-induced structural relaxation and the concepts of fictive stress. ${ }^{10)}$ Our model calculation reproduces the experimental result of the Pd-based and $\mathrm{Zr}$-based glass alloys fairly well, in particular, the development of stress-overshoot behavior. In addition, the model reveals a stress-overshoot and stress-undershoot oscillation at very high strain rate. This oscillatory nonlinear behavior has been observed in many polymer solutions, ${ }^{15,16)}$ and in metallic glasses. ${ }^{9)}$ The model calculation of other nonlinear viscoelastic behaviors, such as stress-relaxation during stress growth, after abrupt cessation of steady-state flow and a stress regrowth after a brief interval of relaxation are also presented.

\section{Experimental Procedures and Results}

Alloy ingots were prepared by arc melting pure metals in a purified argon atmosphere. Cylindrical samples of a $\mathrm{Pd}_{40} \mathrm{Ni}_{10} \mathrm{Cu}_{30} \mathrm{P}_{20}$ and a $\mathrm{Zr}_{55} \mathrm{Al}_{10} \mathrm{Ni}_{5} \mathrm{Cu}_{30}$ alloy glasses $2 \mathrm{~mm}$ in diameter were obtained by melt casting into a copper mold. Glassy structure of the cast samples was confirmed by X-ray diffraction. Thermal properties were measured by differential scanning calorimetry (DSC). The onset of the glass transition temperature, $T_{\mathrm{g}}$, and the onset of crystallization were determined at $0.33 \mathrm{~K} / \mathrm{s}$ to be 575 and $655 \mathrm{~K}$ for the Pd-based alloy glass and 680 and $758 \mathrm{~K}$ for the $\mathrm{Zr}$-based alloy glass, respectively. For a compressive mechanical test, cylindrical samples $2 \mathrm{~mm}$ in diameter $\times 4 \mathrm{~mm}$ in length, were cut from the cast glass alloy and the surfaces were polished parallel. The compression tests were conducted using an Instron type machine.

\section{$2.1 \mathrm{Pd}_{40} \mathrm{Ni}_{10} \mathrm{Cu}_{30} \mathrm{P}_{20}$ glass}

Figure 1 shows the strain-rate dependence of the stressstrain curves at $T=573 \mathrm{~K}$. At low strain rate, $\dot{\varepsilon} \leq 1 \times$ $10^{-3} \mathrm{~s}^{-1}$, the stress, $\sigma$, increases monotonically with strain, $\varepsilon$, and attains a steady-state flow stress, $\sigma_{\mathrm{f}}$. At high strain rate, $\dot{\varepsilon}>5 \times 10^{-3} \mathrm{~s}^{-1}, \sigma$ increases initially attaining a maximum value at strain, $\varepsilon \sim 6 \times 10^{-2}$. It then decreases and attains a steady-state value for $\varepsilon>10 \times 10^{-2}$. The steadystate viscosity, $\eta_{\mathrm{f}}\left(=\sigma_{\mathrm{f}} / 3 \dot{\varepsilon}\right)$, was thus obtained. The strain rate dependence of viscosity, $\eta_{\mathrm{f}}$, and flow stress, $\sigma_{\mathrm{f}}$, are illustrated in Figs. 2(a) and on 2(b), respectively. As shown in Fig. 2(a), $\eta_{\mathrm{f}}$ remains constant for $\dot{\varepsilon}<\dot{\varepsilon}_{\mathrm{c}}$ and then decreases drastically for $\dot{\varepsilon}>\dot{\varepsilon}_{\mathrm{c}}$. At much higher $\dot{\varepsilon}, \log \eta_{\mathrm{f}}$ vs. $\log \dot{\varepsilon}$ curves show a slope of -1 . We define here the critical strain rate, $\dot{\varepsilon}_{\mathrm{c}}$, at the intersection of viscosity $\eta_{\mathrm{f}}(\dot{\varepsilon})$ lines in the low and high $\dot{\varepsilon}$ regime. The term $\dot{\varepsilon}_{\mathrm{c}}$ is also the critical strain rate, above which the stress-strain curves show a

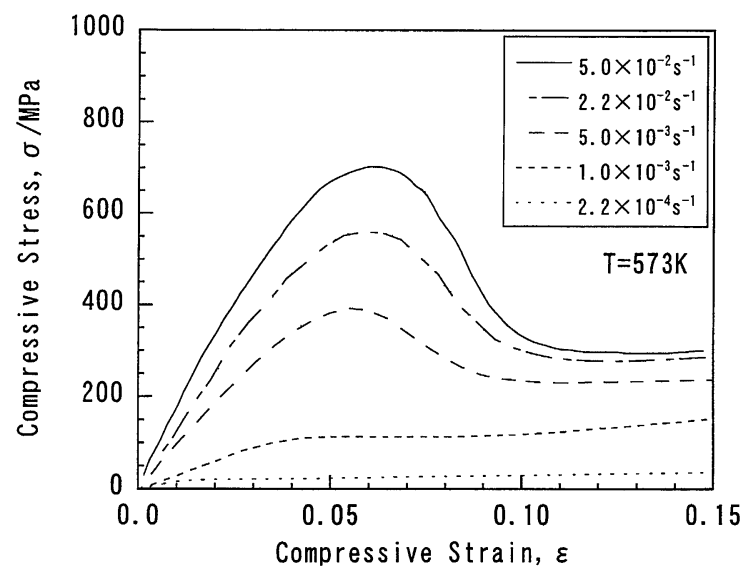

Fig. 1 The stress, $\sigma$, versus strain, $\varepsilon$, curves for the Pd-based alloy glass subjected to various strain rate, $\dot{\varepsilon}$, at $T=573 \mathrm{~K}$.

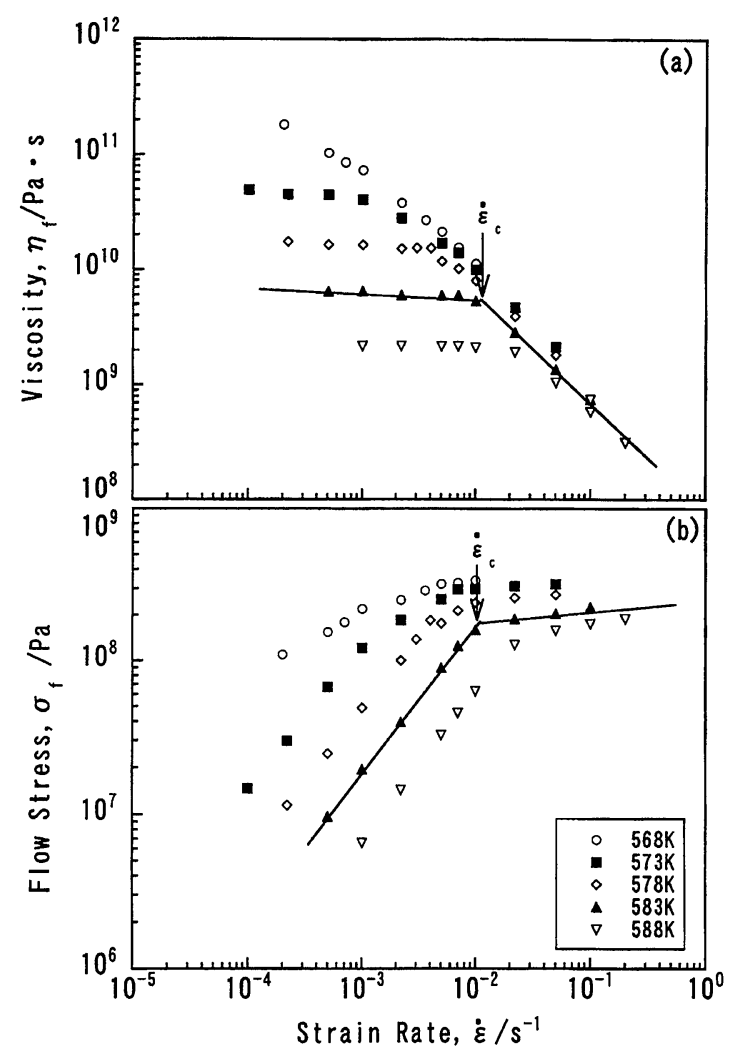

Fig. 2 The strain rate, $\dot{\varepsilon}$, dependence of viscosity, $\eta_{\mathrm{f}}(\mathrm{a})$, and flow stress, $\sigma_{\mathrm{f}}$ (b), at various temperatures: $568 \mathrm{~K}(\bigcirc), 573 \mathrm{~K}(\mathbf{\square}), 578 \mathrm{~K}(\diamond), 583 \mathrm{~K}(\mathbf{\Delta})$ and $588 \mathrm{~K}(\nabla)$. The term, $\dot{\varepsilon}_{\mathrm{c}}$, is the critical strain rate at the intersection of two viscosity lines.

stress-overshoot (Fig. 1). The Newtonian viscosity, $\eta_{\mathrm{N}}$, decreases by two orders of magnitude from $\sim 3 \times 10^{11} \mathrm{~Pa} \cdot \mathrm{s}$ at $T=568 \mathrm{~K}$ to $2 \times 10^{9} \mathrm{~Pa} \cdot \mathrm{s}$ at $T=588 \mathrm{~K}$, and the critical strain rate, $\dot{\varepsilon}_{\mathrm{c}}$, appears vary nearly inversely proportional to $\eta_{\mathrm{N}}$, from $2 \times 10^{-4} \mathrm{~s}^{-1}$ to $3 \times 10^{-2} \mathrm{~s}^{-1}$. The corresponding strain-rate dependence of flow stress, $\sigma_{\mathrm{f}}\left(=3 \dot{\varepsilon} \eta_{\mathrm{f}}\right)$, is shown in Fig. 2(b). The flow stress, $\sigma_{\mathrm{f}}$, increases linearly with $\dot{\varepsilon}$ initially then deviates from the linearity and attains a plateau at $\dot{\varepsilon}>\dot{\varepsilon}_{\mathrm{c}}$. It may be noted that for the temperature range studied at very high strain rate, e.g., $\dot{\varepsilon}>5 \times 10^{-2} \mathrm{~s}^{-1}$, the viscosities and flow stresses tend to merge together and vary slightly with temper- 


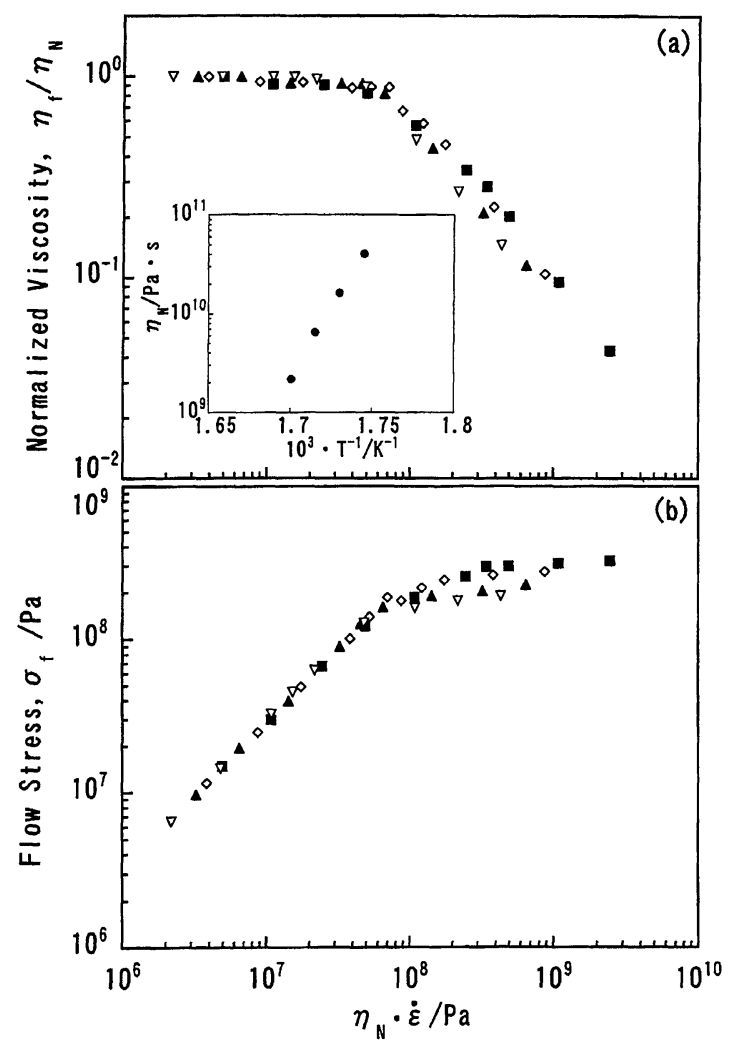

Fig. 3 The normalized viscosity, $\eta_{\mathrm{f}} / \eta_{\mathrm{N}}$ (a), and the flow stress, $\sigma_{\mathrm{f}}$ (b) versus $\eta_{\mathrm{N}} \dot{\varepsilon}$, the product of Newtonian viscosity, $\eta_{\mathrm{N}}$, and strain rate, $\dot{\varepsilon}$, at various temperatures: $568 \mathrm{~K}(\bigcirc), 573 \mathrm{~K}(\boldsymbol{\square}), 578 \mathrm{~K}(\diamond), 583 \mathrm{~K}(\boldsymbol{\Delta})$ and $588 \mathrm{~K}$ $(\nabla)$. The temperature dependence of $\eta_{\mathrm{N}}$ is shown in the insert.

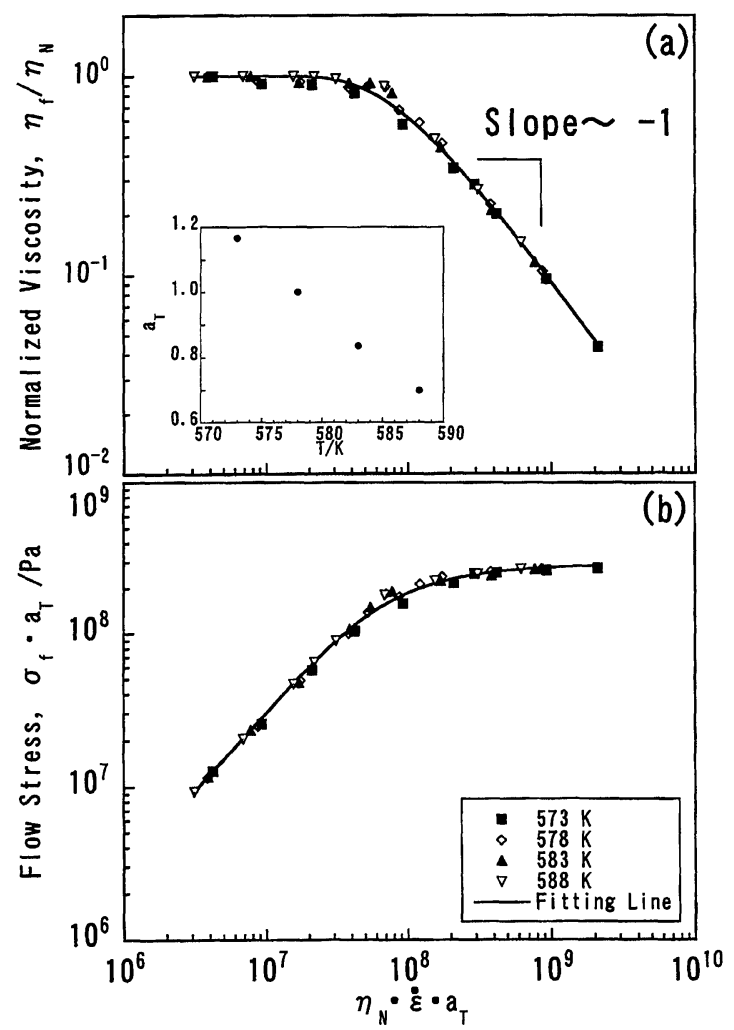

Fig. 4 Master curves of the normalized viscosity, $\eta_{\mathrm{f}} / \eta_{\mathrm{N}}$ (a) and flow stress, $\sigma_{\mathrm{f}}(\mathrm{b})$ in terms of the product, $\eta_{\mathrm{N}} \dot{\varepsilon}$, at $T=758 \mathrm{~K}$. Shift factors, $a_{\mathrm{T}}$, are shown in the insert. The curves are fitted with a relaxation function of the form, $1-\exp \left(-1 / t_{2} \dot{\varepsilon}\right)$, with the time constant $t_{2}=180 \mathrm{~s}$. ature in contrast with the large change in the Newtonian viscosity, $\eta_{\mathrm{N}}$. The limiting maximum flow stress, $\sigma^{*}$, decreases slightly with increasing temperature from $3.8 \times 10^{8} \mathrm{~Pa} \cdot \mathrm{s}$ at $T=568 \mathrm{~K}$ to $2.1 \times 10^{8} \mathrm{~Pa} \cdot \mathrm{s}$ at $T=588 \mathrm{~K}$.

The normalized viscosity, $\eta_{\mathrm{f}} / \eta_{\mathrm{N}}$, and the flow stress, $\sigma_{\mathrm{f}}$, plotted against the product, $\eta_{\mathrm{N}} \dot{\varepsilon}$ of strain rate and Newtonian viscosity are shown in Figs. 3(a) and (b), respectively. The temperature dependence of the viscosity, $\eta_{\mathrm{N}}$, is shown in the insert. The viscosity $\eta_{\mathrm{N}}=\eta_{0} \exp [Q / k T]$ with $\eta_{0}=3.75 \times$ $10^{-48} \mathrm{~Pa} \cdot \mathrm{s}$ and $Q \sim 5 \mathrm{eV}$. As shown in Figs. 3(a) and (b), $\eta_{\mathrm{f}} / \eta_{\mathrm{N}}$ and $\sigma_{\mathrm{f}}$ in the Newtonian regime, i.e., $\eta_{\mathrm{N}} \dot{\varepsilon}>10^{8} \mathrm{~Pa}$, decrease with increasing temperature. By horizontal shift the $\log \left(\eta_{\mathrm{f}} / \eta_{\mathrm{N}}\right)$ vs $\log \left(\eta_{\mathrm{N}} \dot{\varepsilon}\right)$ curves to $T=578 \mathrm{~K}$, a master curve is obtained as shown in Fig. 4(a). The shift factors, $a_{\mathrm{T}}$, are shown in the insert. As stated previously, at high $\eta_{\mathrm{N}} \dot{\varepsilon}$, the $\log \left(\eta_{\mathrm{f}} / \eta_{\mathrm{N}}\right)$ vs $\log \left(\eta_{\mathrm{N}} \dot{\varepsilon} \cdot a_{\mathrm{T}}\right)$ curve shows a slope of -1 . Using the same shift factors, we are able to obtain a master curve in terms of $\sigma_{\mathrm{f}} \cdot a_{\mathrm{T}}$ and $\eta_{\mathrm{N}} \dot{\varepsilon} \cdot a_{\mathrm{T}}$ shown in Fig. 4(b). Since $\log \left(\sigma_{\mathrm{f}} \cdot a_{\mathrm{T}}\right)=\log \left(\eta_{\mathrm{N}} \dot{\varepsilon} \cdot a_{\mathrm{T}}\right)=\log \left(\eta_{\mathrm{f}} / \eta_{\mathrm{N}}\right)+\log \left(\eta_{\mathrm{N}} \dot{\varepsilon} \cdot a_{\mathrm{T}}\right)$, in fact, the shape of $\log \left(\eta_{\mathrm{f}} / \eta_{\mathrm{N}}\right)$ vs $\log \left(\eta_{\mathrm{N}} \dot{\varepsilon} \cdot a_{\mathrm{T}}\right)$ and $\log \left(\sigma_{\mathrm{f}} \cdot a_{\mathrm{T}}\right)$ vs $\log \left(\eta_{\mathrm{N}} \dot{\varepsilon} \cdot a_{\mathrm{T}}\right)$ master curves are identical upon rotating each other by $45^{\circ}$.

\section{$2.2 \mathrm{Zr}_{55} \mathrm{Al}_{10} \mathrm{Ni}_{5} \mathrm{Cu}_{30}$ glass}

Figure 5 shows the strain-rate dependence of stress-strain curves (S-S curves) at $T=680 \mathrm{~K}$. We defined here a true compressive stress $\sigma=(F / A)\left(1+\Delta l / l_{0}\right)$, and a true compressive strain $\varepsilon=-\left(\Delta l / l_{0}\right)\left(1-\Delta l / l_{0}\right)$, where $\Delta l=l-l_{0}<$ 0 , where $F$ is applied force and $A$ is an initial cross-section area. A correction for the length change, $\Delta l$, was made by assuming the alloy to be an incompressive liquid. At low strainrates, $\dot{\varepsilon} \leq 1.0 \times 10^{-3} \mathrm{~s}^{-1}$, the stress increased monotonically with strain and attained a steady-state flow stress, $\sigma_{\mathrm{f}}$. On the other hand, at high strain-rates $\dot{\varepsilon} \geq 5.0 \times 10^{-3} \mathrm{~s}^{-1}$, the stress increased to a maximum value, then decreased and attained an almost steady value of $\sigma_{\mathrm{f}}$. This phenomenon is known as stress-overshoot. It has been observed in both compression ${ }^{9)}$ and tension ${ }^{17,18)}$ modes.

The strain-rate dependence of $\sigma_{\mathrm{f}}$ and the steady-state viscosity, $\eta_{\mathrm{f}}\left(=\sigma_{\mathrm{f}} / 3 \dot{\varepsilon}\right)$, are illustrated in Figs. 6(a) and (b), respectively. At a given temperature, $\sigma_{\mathrm{f}}$ increased monotonically with increasing strain-rate, and attained an approximately constant flow stress, $\sigma^{*}$, at high strain-rates, where the stress-overshoot phenomenon appeared. This relationship corresponds to Newtonian viscous-flow at the lower strainrates and non-Newtonian viscous-flow at the higher ones. The Newtonian viscosity, $\eta_{\mathrm{N}}$, decreased by one order of magnitude from $\sim 1 \times 10^{12} \mathrm{~Pa} \cdot \mathrm{s}$ at $T=670 \mathrm{~K}$ to $1 \times 10^{11} \mathrm{~Pa} \cdot \mathrm{s}$ at $T=690 \mathrm{~K}$. The temperature range in the present experiments was not enough to apply the Vogel-Fulcher-Tammann (VFT) type formula. If an Arrhenius type equation is applied, the Newtonian viscosity is given by $\eta_{\mathrm{N}}=\eta_{0} \exp [Q / k T]$ with $\eta_{0}=2.9 \times 10^{-27} \mathrm{~Pa} \cdot \mathrm{s}$ and $Q \sim 5 \mathrm{eV}$. It is noted that at very high strain-rates of $\dot{\varepsilon}>3 \times 10^{-2} \mathrm{~s}^{-1}, \eta_{\mathrm{f}}$ and $\sigma_{\mathrm{f}}$ in the nonlinear regime tended to merge together and become almost independent of temperature in contrast with their strong dependence on temperature in the linear regime. The maximum flow-stress, $\sigma^{*}$, decreases slightly with increasing temperature from $6 \times 10^{8} \mathrm{~Pa}$ at $T=660 \mathrm{~K}$ to $4 \times 10^{8} \mathrm{~Pa}$ at $T=690 \mathrm{~K}$.

To demonstrate the relationship between $\eta_{\mathrm{f}}$ and $\dot{\varepsilon}$, the nor- 


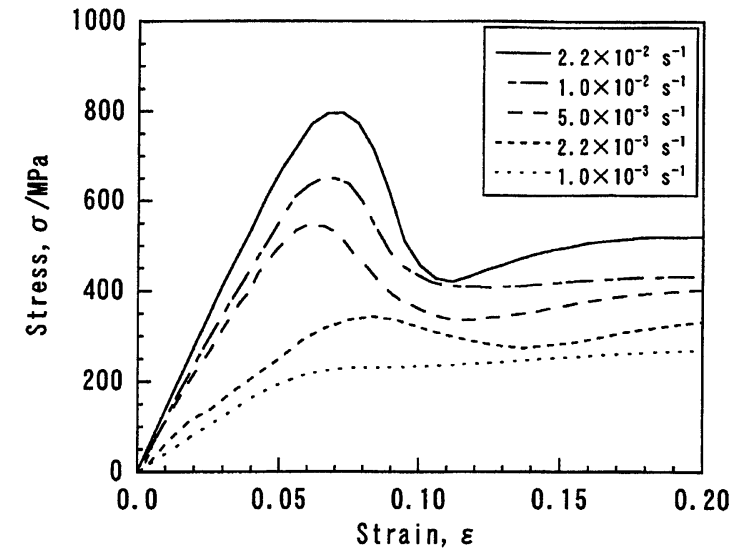

Fig. 5 Stress-Strain curves of the Zr-based alloy glass at various strain rates in a temperature of $680 \mathrm{~K}$.

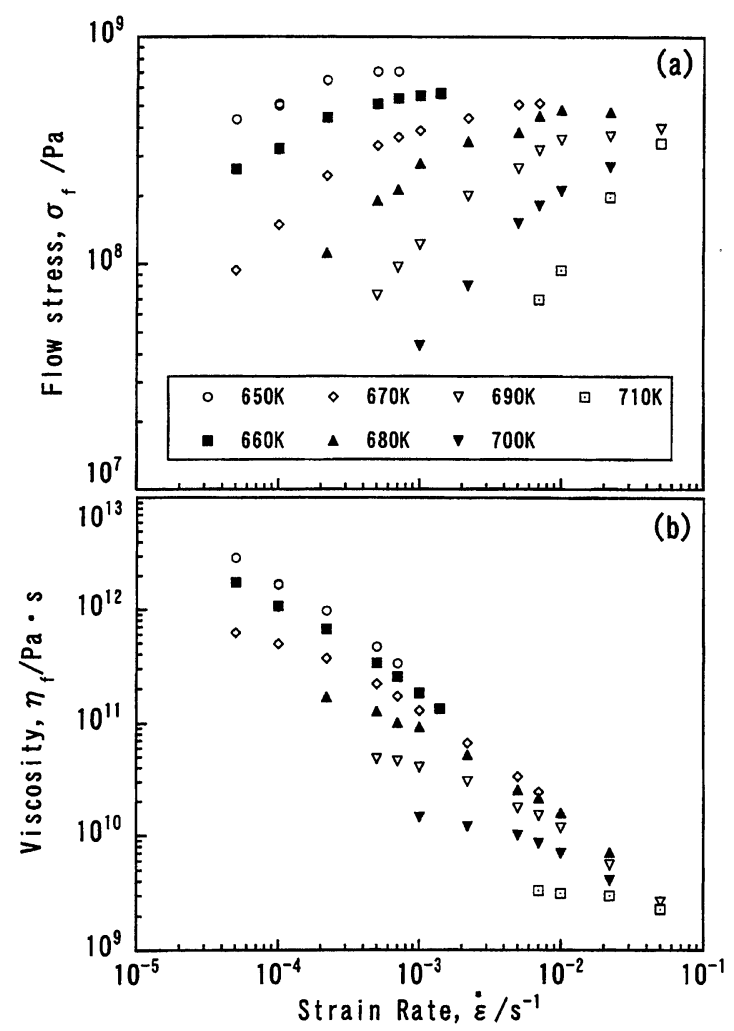

Fig. 6 The strain rate dependence of the steady-state flow stress, $\sigma_{\mathrm{f}}(\mathrm{a})$, and viscosity, $\eta_{\mathrm{f}}(\mathrm{b})$ at various temperatures: $650 \mathrm{~K}(\bigcirc), 660 \mathrm{~K}(\mathbf{\square}), 670 \mathrm{~K}(\diamond)$, $680 \mathrm{~K}(\mathbf{\Delta}), 690 \mathrm{~K}(\nabla), 700 \mathrm{~K}(\boldsymbol{\nabla})$ and $710 \mathrm{~K}(\square)$.

malized viscosity, $\eta_{\mathrm{f}} / \eta_{\mathrm{N}}$, and $\sigma_{\mathrm{f}}$ were plotted against $\eta_{\mathrm{N}} \dot{\varepsilon}$, the product of the strain rate and the Newtonian viscosity, as shown in Figs. 7(a) and (b), respectively. $\eta_{\mathrm{f}} / \eta_{\mathrm{N}}$ decreased with increasing temperature in the non-Newtonian regime, $\eta_{\mathrm{N}} \dot{\varepsilon}>3 \times 10^{7} \mathrm{~Pa} . \eta_{\mathrm{f}} / \eta_{\mathrm{N}}$ and $\sigma_{\mathrm{f}}$ at the corresponding $\eta_{\mathrm{N}} \dot{\varepsilon}$ are lower at higher temperature. By horizontal shift of the $\log \left(\eta_{\mathrm{f}} / \eta_{\mathrm{N}}\right)$ versus $\log \left(\eta_{\mathrm{N}} \dot{\varepsilon}\right)$ curves to that at $T=680 \mathrm{~K}$, a master curve was obtained as illustrated in Fig. 8(a). The shift factors, $a_{\mathrm{T}}$, are shown in the insert. Using the same shift factors, we were able to obtain a master curve in terms of $\sigma_{\mathrm{f}}$ and $\eta_{\mathrm{N}} \dot{\varepsilon}$ as shown in Fig. 8(b).

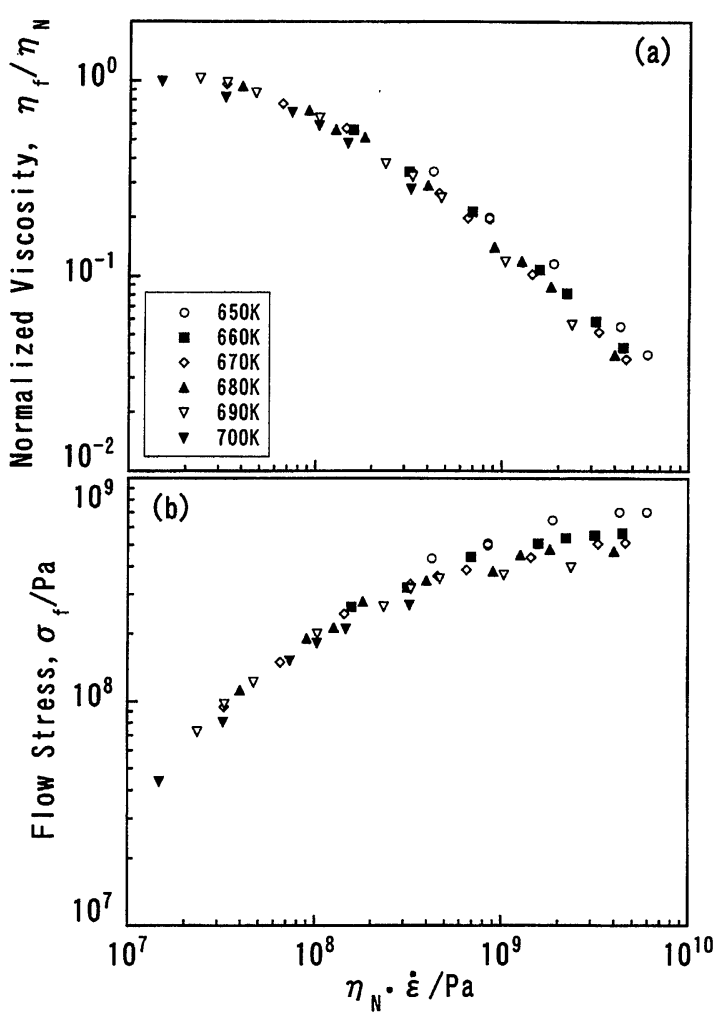

Fig. 7 The normalized viscosity, $\eta_{\mathrm{f}} / \eta_{\mathrm{N}}(\mathrm{a})$, and the flow stress, $\sigma_{\mathrm{f}}(\mathrm{b})$ versus $\eta_{\mathrm{N}} \dot{\varepsilon}$, the product of Newtonian viscosity, $\eta_{\mathrm{N}}$, and strain rate, $\dot{\varepsilon}$, at various temperatures: $650 \mathrm{~K}(\bigcirc), 660 \mathrm{~K}(\boldsymbol{\square}), 670 \mathrm{~K}(\diamond), 680 \mathrm{~K}(\boldsymbol{\Delta}), 690 \mathrm{~K}$ $(\nabla), 700 \mathrm{~K}(\boldsymbol{\nabla})$.

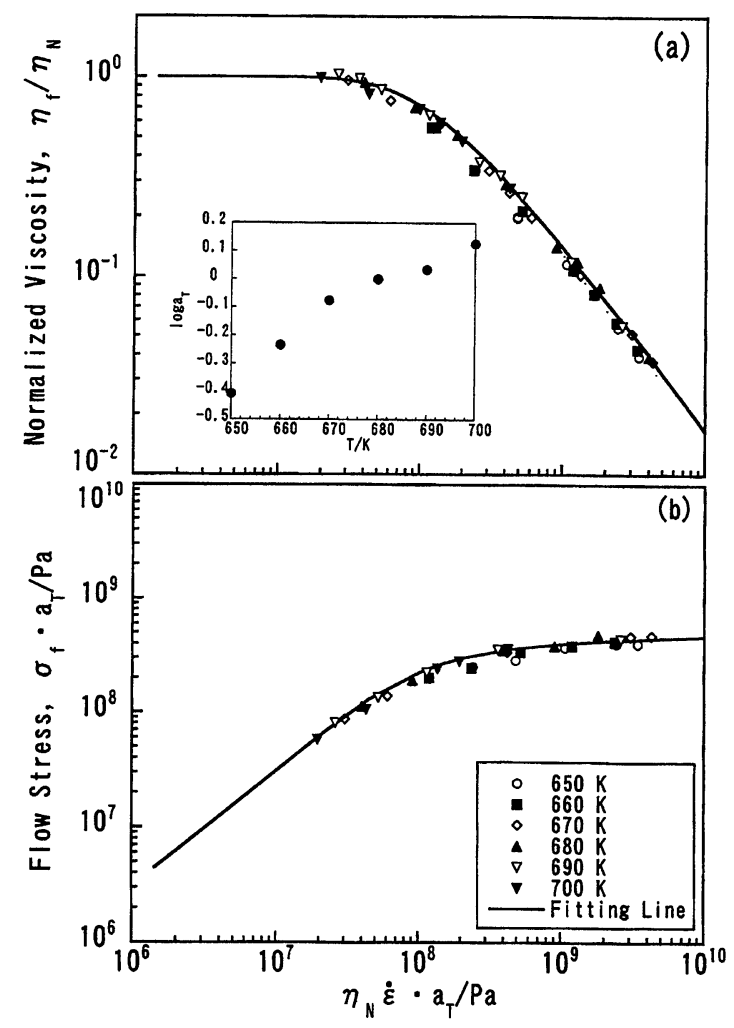

Fig. 8 Master curves of $\eta_{\mathrm{f}} / \eta_{\mathrm{N}}$ (a) and $\sigma_{\mathrm{f}}(\mathrm{b})$ in terms of the product, $\eta_{\mathrm{N}} \dot{\varepsilon}$, at $T=680 \mathrm{~K}$. Shift factors, $a_{\mathrm{T}}$, are shown in the insert of (a). The curves are fitted with eq. (2) with $\beta=0.96$. 


\subsection{Stress Relaxation Functions}

When a visoelastic material is deformed at a constant shear rate, $\dot{\gamma}$, at first the stress rises linearly with time, $\tau_{\mathrm{f}}=$ $G_{\infty} \cdot \dot{\gamma} t=G_{\infty} \gamma(t)$, as a liquid takes time to respond structurally. Since a liquid will not support a static stress, it flows and the rate of increase of the stress decreases. It attains a limiting steady-state value, $\tau_{\mathrm{s}}=G_{\infty} \lambda_{\mathrm{N}} \dot{\gamma}=\eta_{\mathrm{N}} \dot{\gamma}$, where $\lambda_{\mathrm{N}}$ is the Newtonian shear relaxation time. In theory then, the strain rate is increases without limit, then $\tau_{\mathrm{s}}$ will also become higher without limit. However, the stress will reach a critical level, $\tau_{\mathrm{c}}$, at which a substantial structural breakdown takes place. For example, the initial cooperative domains may break down, or the shear reorganizes the liquid directionally to facilitate the flow. The new structure has a shorter relaxation time $\lambda^{\prime}<\lambda_{N}, \tau_{c}=G_{\infty} \lambda^{\prime} \dot{\gamma}$ and, $\eta_{\mathrm{f}}=\tau_{\mathrm{c}} / \dot{\gamma}=G_{\infty} \lambda^{\prime}<\eta_{\mathrm{N}}$. Appreciable decreases in viscosity, i.e., non-Newtonian flow, will be observed. Ideally the structure of the liquid changes through relaxation even at low strain rate and flow stress. It is at a critical stress, $\tau_{c}$, that an appreciable deviation in $\eta_{\mathrm{f}}$ from the Newtonian flow is observable. With a further increase in strain rate, structure changes further and the viscosity, $\eta_{\mathrm{f}}$, and the shear relaxation time, $\lambda^{\prime}$ decrease accordingly while the flow shear stress, $\tau$, may increase slightly. The steady-state stress asymptotically approaches a maximum at very high shear rate. The limiting stress, $\tau^{*}$, may be interpreted as the actual cohesive strength of the materials. The maximum elastic shear strain, $\gamma_{\mathrm{e}}^{*} \cong \tau^{*} / G_{\infty}$, which the liquid can support, is thus a characteristic of materials and may depend slightly on atomic configuration of the liquid. The maximum flow strength, $\tau^{*}$, in general, is several times smaller than the ultimate fracture strength of the solid glass, $\tau_{\mathrm{u}}$, the fracture strength of a glass when $\dot{\gamma} \gg \lambda_{\mathrm{N}}^{-1}$.

We arrived at two end conditions for the flow stress,

$\tau_{\mathrm{s}}=G_{\infty} \lambda_{\mathrm{N}} \dot{\gamma} \cong \eta_{\mathrm{N}} \dot{\gamma} \quad$ for $\quad \dot{\gamma}<\tau_{\mathrm{c}} / G_{\infty} \lambda_{\mathrm{N}}<\tau^{*} / G_{\infty} \lambda_{\mathrm{N}}$,

$\tau_{\mathrm{s}}=\tau^{*} \cong G_{\infty} \gamma_{\mathrm{e}}^{*}$ for $\quad \dot{\gamma}>\tau^{*} / G_{\infty} \lambda_{\mathrm{N}}$.

The conditions set forth above can be approximated by, considering the relaxation mechanism for the non-Newtonian flow proposed above, a simple stress relaxation function,

$$
\tau_{\mathrm{s}}=\tau^{*} t_{1} \dot{\gamma}\left[1-\exp \left(-\left(1 / t_{1} \dot{\gamma}\right)^{\beta}\right)\right],
$$

and

$$
\left.\eta_{\mathrm{f}} / \eta_{\mathrm{N}}=1-\exp \left[-\left(1 / t_{1} \dot{\gamma}\right)^{\beta}\right)\right]
$$

where $t_{1}=G_{\infty} \lambda_{\mathrm{N}} / \tau^{*}=\lambda_{\mathrm{N}} / \gamma_{\mathrm{e}}^{*}$. We found the Young's modulus of the Pd-based glass, $E_{\infty}=3 G_{\infty} \approx 5 \times 10^{10} \mathrm{~Pa}$ and estimated the maximum elastic strain of the liquid, $\gamma_{\mathrm{e}}^{*}=$ $\tau^{*} / G_{\infty} \approx \sqrt{3} \sigma^{*} / E_{\infty}=10^{-2}$. Similarity for the $\mathrm{Zr}$-based glass, $E_{\infty} \approx 8 \times 10^{10} \mathrm{~Pa}$ and $\gamma_{\mathrm{e}}^{*} \approx 10^{-2}$. The experimental data are fitted with eqs. (2a) and (2b) for the Pd-based glass with $\beta=1$ and for the $\mathrm{Zr}$-based glass with $\beta=0.96$ and shown in Figs. 4 and 8 , respectively. In the fitting, we adopt compressive stress, $\sigma_{\mathrm{f}}$, and compressive strain rate, $\dot{\varepsilon}$, in place of $\tau$ and $\dot{\gamma}$ in eqs. (2a) and (2b). It simply effects upon the time constant, $t_{1}$, accordingly. The agreements are very satisfactory.

Taking $\eta_{\mathrm{f}} / \eta_{\mathrm{N}}=\lambda_{\mathrm{f}} / \lambda_{\mathrm{N}}$ and $\sigma_{\mathrm{f}} / \sigma^{*}=\tau_{\mathrm{f}} / \tau^{*}$, combing eqs. (2a) and (2b), we arrived at,

$$
\sigma_{\mathrm{f}} / \sigma^{*}=\left(\tau_{\mathrm{f}} / \tau_{\mathrm{N}}\right) \cdot\left[-\ln \left(1-\tau_{\mathrm{f}} / \tau_{\mathrm{N}}\right)\right]^{-1 / \beta}
$$

Equation (3) fits very well with the experimental data of Kato et al.$^{9,10)}$ for the Pd-based alloy glass with $\beta=1.0 \mathrm{Zr}$-based alloy glass with $\beta=0.96$ as shown in Figs. 9(a) and (b), respectively. $\lambda_{\mathrm{f}} / \lambda_{\mathrm{N}}$ remains nearly constant for $\sigma_{\mathrm{f}} / \sigma^{*}<1 / 4$ and decreases rapidly approaching zero as $\sigma_{\mathrm{f}} / \sigma^{*}$ approaching 1 . To avoid a singularity at $\sigma_{\mathrm{f}} / \sigma^{*}=1$ for the Pd-based alloy glass, we adopt a linear extension of eq. (3) with the expression $\ln \left(\lambda_{\mathrm{f}} / \lambda_{\mathrm{N}}\right)=a+b \cdot \ln \left(\sigma_{\mathrm{f}} / \sigma^{*}\right)$ for $\sigma_{\mathrm{f}} / \sigma^{*} \geq 0.95$ (Fig. 9(a)).

\section{Stress-Induced Structural Relaxation and the Con- cept of Fictive Stress}

In theoretical and experimental studies on some polymer systems, ${ }^{13,15,16)}$ it has been shown that an entanglement plays an important role in the flow and melts. At high shear-rates,
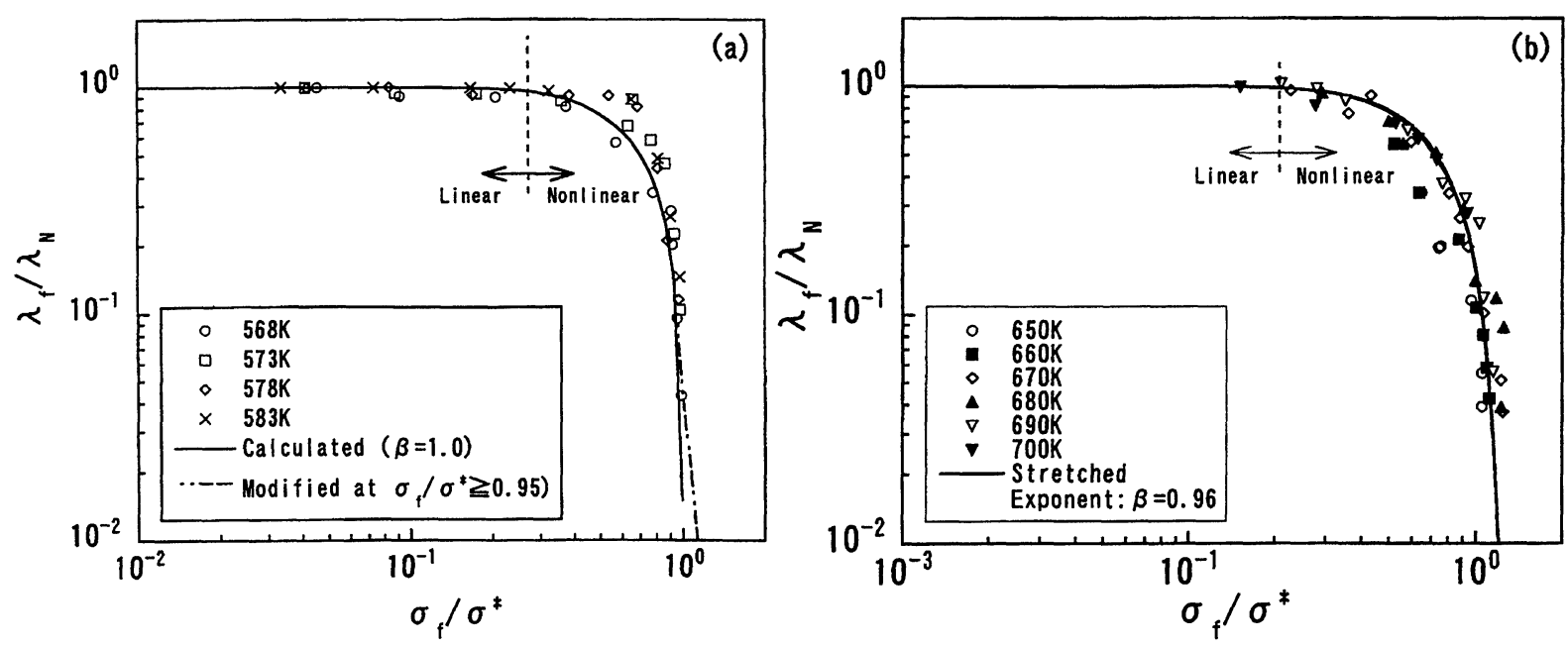

Fig. 9 The relationship between the normalized relaxation time, $\lambda_{\mathrm{f}} / \lambda_{\mathrm{N}}$, versus the normalized flow stress, $\sigma_{\mathrm{f}} / \sigma^{*} \mathrm{of}_{\mathrm{f}} \mathrm{Pd} \mathrm{d}_{40} \mathrm{Ni}_{10} \mathrm{Cu}_{30} \mathrm{P}_{20}$ alloy glass (a), and of $\mathrm{Zr}_{55} \mathrm{Al}_{10} \mathrm{Ni}_{5} \mathrm{Cu}_{30}$ alloy glass (b). The solid curve is the theoretical fit of eq. (3). 
a time required to form entanglements is longer than a transit time of a group of segments over a potential entanglement site. Hence, entanglements do not have enough time to form and viscosity decreases. Concurrently, the initial structure is broken down, and a new steady-state structure is created, in which the time to form entanglements is comparable to the transit time. It is a reconfiguration of entanglements that causes the non-Newtonian flow. The theories predict that the non-Newtonian viscosity at very high strain-rates follows a power law, i.e. $\eta_{\mathrm{f}} \sim \dot{\gamma}^{-n}$ with $n=6 / 7^{19)}$ and $3 / 4,{ }^{13)}$ where $\dot{\gamma}(=\sqrt{3} \dot{\varepsilon})$ is a shear rate. On the other hand, glassy alloy does not have complex structures, such as entanglements in polymer melts. The supercooled liquid of glassy alloy has simple atomic structure with clusters, so that the distribution of relaxation times is very narrow. The power-law parameter $n$ is approximately 0.96 in the Zr-based alloy and 1.0 in the Pd-based alloy for instance. ${ }^{9,10)}$ Recent computer simulations in Lennard-Jones glasses ${ }^{12,13)}$ reveal that structure changes occur even in a simple liquid by the shear action. The changes are reorganization of the liquid directionality, and this behavior results in facilitation of the viscous flow. The steady-state shear stress, $\tau_{\mathrm{f}}\left(=\sigma_{\mathrm{f}} / \sqrt{3}\right)$, approaches asymptotically to a maximum value, $\tau^{*}$, at very high shear-rates. A general theory, regardless of differences in molecular structures among glass polymers, inorganic glasses and atomic metallic glasses, is that there exists a steady-state flow structure of a liquid corresponding to a given strain rate and stress. As seen in Fig. 9, there exists a corresponding normalized viscosity, $\eta_{\mathrm{f}} / \eta_{\mathrm{N}}$, or relaxation time, $\lambda_{\mathrm{f}} / \lambda_{\mathrm{N}}$, to a given steady-state flow stress, $\sigma_{\mathrm{f}}$, in a liquid. We hereby introduce an additional structural parameter, a fictive stress, $\sigma_{\mathrm{f}}$, analogous to fictive temperature, $T_{\mathrm{f}}$. In other words, we introduce relaxation time or the nonlinear dependence of the relaxation time to change in the stressinduced structure.

\section{Fictive Stress and Model Calculations}

Considering a simple Maxwell Model, under tension (or compression), the stress relaxation equation is given by,

$$
\dot{\sigma}=E \dot{\varepsilon}-\frac{\sigma}{\lambda_{\text {fic }}},
$$

where $\sigma, \varepsilon, \lambda_{\text {fic }}$ and $E$ are stress, strain, fictive relaxation time and Young's modulus respectively, and $\dot{\sigma}$ and $\dot{\varepsilon}$ are stress and strain rates, respectively. The relaxation time, $\lambda_{\text {fic }}$, depends on fictive stress, $\sigma_{\text {fic }}$. For constant strain rate, $\dot{\varepsilon}$, and in Newtonian flow regime, $\lambda_{\text {fic }}=\lambda_{\mathrm{f}}=\lambda_{\mathrm{N}}$ and the viscosity $\eta_{\mathrm{N}} \cong E \lambda_{\mathrm{N}} / 3$ is constant. The solution of eq. (4) is $\sigma(t)=E \lambda_{\mathrm{N}} \dot{\varepsilon}\left[1-\exp \left(-t / \lambda_{\mathrm{N}}\right)\right] . \sigma(t)$ increases monotonically and attains a steady-state value, where we deal with a linear viscoelastic system. In non-linear viscoelastic regime, a sudden change in the magnitude of stress results in changing in some physical properties e.g., causing elastic deformation, but it does not change the liquid structure and thus various relaxation times at $t=0$, but it will be followed by its evolution to a new equilibrium structure and relaxation times. The rate of equilibrium for fictive stress, $\sigma_{\text {fic }}=\sigma_{\mathrm{f}}$, is

$$
d \sigma_{\mathrm{f}} / d t=\left(\sigma-\sigma_{\mathrm{f}}\right) / \lambda_{\mathrm{fic}},
$$

where $\lambda_{\text {fic }}$ is the time constant of structural relaxation (it may differ from the relaxation time for shear, $\tau_{\mathrm{f}}$, but is proportional to $\tau_{\mathrm{f}}$ and a function of $\sigma_{\mathrm{f}}$ ). For present calculations, we take $\lambda_{\text {fic }}=\lambda_{\mathrm{f}}$. To facilitate the computation, we rewrite eq. (3) for $\lambda_{\mathrm{f}} / \lambda_{\mathrm{N}}$ as,

$$
\begin{gathered}
d \lambda_{\mathrm{f}} / d t=\left(\lambda_{\mathrm{N}} / \sigma^{*}\right) \cdot f\left(\lambda_{\mathrm{f}} / \lambda_{\mathrm{N}}\right) \cdot d \sigma_{\mathrm{f}} / d t, \\
f(x)=\frac{(1-x)[-\ln (1-x)]^{1+1 / \beta}}{(1-x)[-\ln (1-x)]-x} .
\end{gathered}
$$

Computations using eqs. (4), (5) and (6), the stress-strain curves for Pd-based glass with $\beta=1.0$ at $T=573 \mathrm{~K}$ at various strain rates, $\dot{\varepsilon}$, are shown in Fig. 10. In the calculations, the Young's modulus $E=20 \mathrm{GPa}$, taking from the initial slope in $\sigma$ vs. $\varepsilon$ curve for $\dot{\varepsilon}=5.0 \times 10^{-2} \mathrm{~s}^{-1}$ (Fig. 1), $\sigma^{*}=280 \mathrm{MPa}$ and $\lambda_{\mathrm{N}}=3 \mathrm{~s}$. Here we take $\lambda_{\text {fic }}=k \lambda_{\mathrm{f}}$ with $k=1$. At low strain rate, $\dot{\varepsilon}=1.0 \times 10^{-3} \mathrm{~s}^{-1}$, the flow is Newtonian and $\lambda_{\mathrm{f}}=\lambda_{\mathrm{N}}$ remains constant. At slightly higher $\dot{\varepsilon}=2.2 \times 10^{-3} \mathrm{~s}^{-1}, \sigma$ appears to increase monotonically with $\varepsilon$. A close examination, however, reveals $\sigma$ deviated from a linear viscoelastic behavior. As shown in Fig. 10(c), the relaxation time $\lambda_{\mathrm{f}}$ decreases from $3 \mathrm{~s}$ and attains a constant value of $\sim 2.75$ s for $\varepsilon \geq 4 \times 10^{-2}$. Correspondingly, $\sigma_{\mathrm{f}}($ Fig. 10(b)) lags behind $\sigma$ slightly in a regime for $\varepsilon<4 \times 10^{-2}$. The deviation from a linear viscoelastic behavior showing a slight stress-overshoot can also be seen in the corresponding ex-

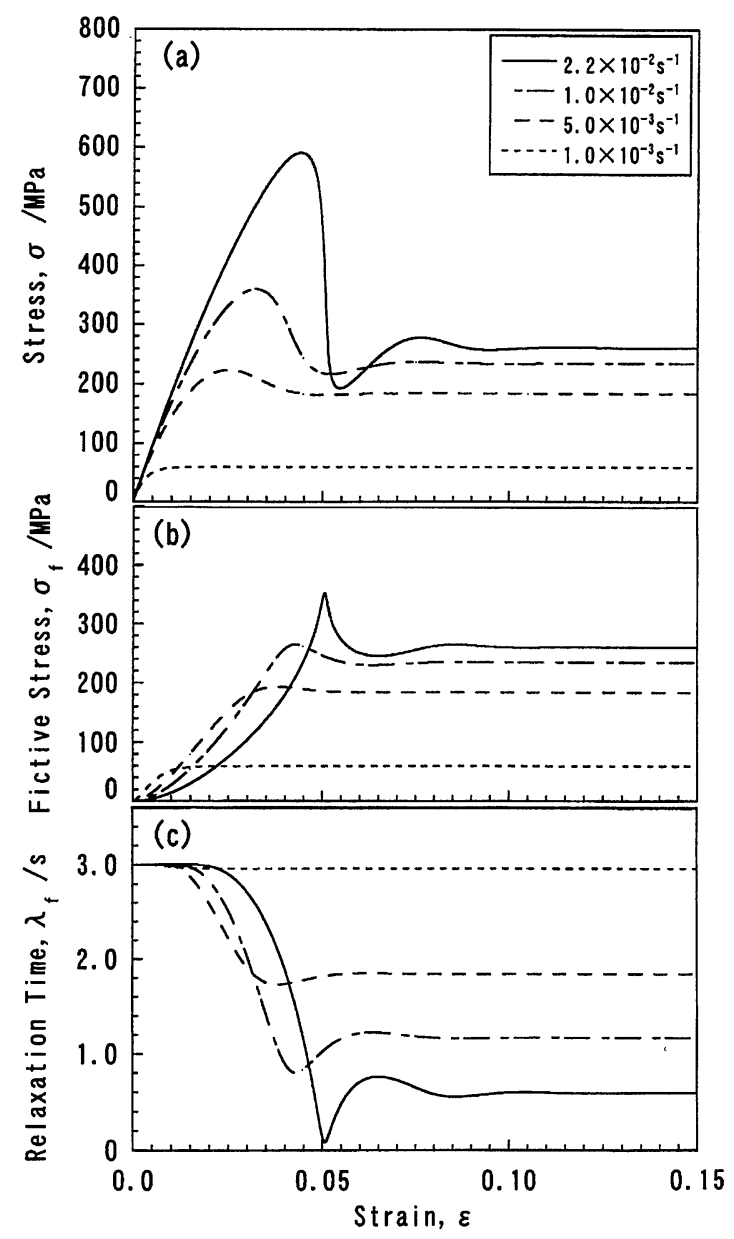

Fig. 10 The calculated stress growth of the Pd-based alloy glass corresponding to Fig. 1, stress, $\sigma$ (a), fictive stress, $\sigma_{\mathrm{f}}(\mathrm{b})$, and relaxation time, $\lambda_{\mathrm{f}}(\mathrm{c})$. 


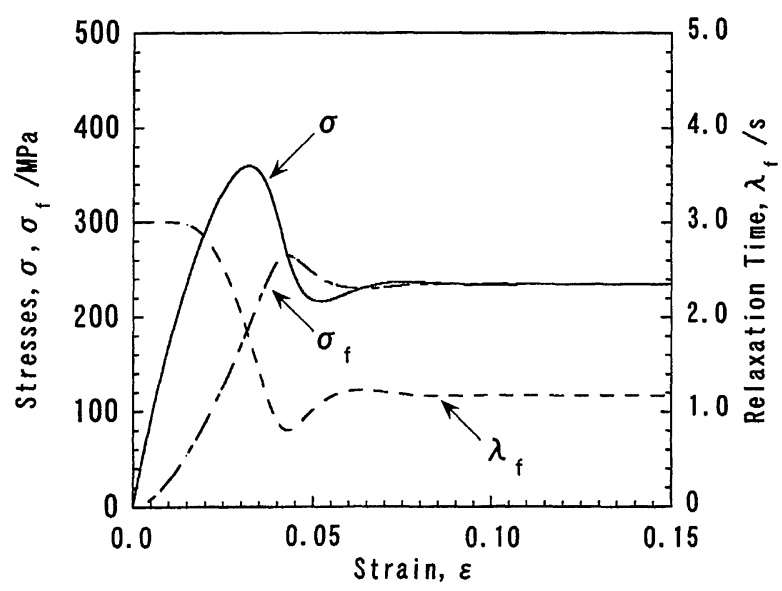

Fig. 11 The relationship among $\sigma, \sigma_{\mathrm{f}}$ and $\lambda_{\mathrm{f}}$ in the stress growth process.

perimental data shown in Fig. 1. At higher rate of strain $\dot{\varepsilon}=5.0 \times 10^{-3} \mathrm{~s}^{-1}$, the model calculation reveals stressovershoot as observed in metallic glasses under both compression and tension. Initially, the fictive stress $\sigma_{\mathrm{f}}$ lags behind $\sigma$, i.e., $\sigma-\sigma_{\mathrm{f}}>0$, for $\varepsilon \leq 5.0 \times 10^{-2} \mathrm{~s}^{-1}$, and finally merges with $\sigma$ in the steady state. The corresponding relaxation time, $\lambda_{\mathrm{f}}$, decreases from $3 \mathrm{~s}$ to $1.8 \mathrm{~s}$. At sufficiently high strain rate, as exemplified for $\dot{\varepsilon}=1.0 \times 10^{-2} \mathrm{~s}^{-1}$ and $2.2 \times 10^{-2} \mathrm{~s}^{-1}$, there is a larger overshoot followed by an undershoot and an indication of oscillation. This oscillatory behavior is often seen in polymer solutions ${ }^{15,16)}$ and the latest measurement on the $\mathrm{Zr}$-based glass. ${ }^{9)}$

The relationship between $\sigma, \sigma_{\mathrm{f}}$ and corresponding $\lambda_{\mathrm{f}}$ is illustrated more clearly in Fig. 11. At the beginning of the flow, $\sigma_{\mathrm{f}}$ remains nearly constant and increases gradually, lagging behind $\sigma$ which grows almost linearly with $\varepsilon$. The relaxation constant, $\lambda_{\mathrm{f}}$, remains nearly constant as $\lambda_{\mathrm{f}}$ is nearly constant for $\sigma_{\mathrm{f}}<\sigma^{*} / 4=70 \mathrm{MPa}$. When $\sigma_{\mathrm{f}}>70 \mathrm{MPa}$ or $\varepsilon \sim 2.0 \times 10^{-2}, \lambda_{\mathrm{f}}$ decreases and the flow becomes nonlinear, and the rate of stress growth $\dot{\sigma}$ becomes slower than that expected from linear viscoelasticity conditions. While the stress growth rate $\dot{\sigma}$ decreases as the last term in eq. (4), $\sigma / \lambda_{\mathrm{f}}$ increases, but the growth rate of fictive stress $\dot{\sigma}_{\mathrm{f}}$ as seen by eq. (5) can either increase or decrease. Thus the existence of stress-overshoot cannot be predicted without model computation. It may be noted however, that nonlinear viscoelastic behavior is observed only when $\sigma_{\mathrm{f}}$, and thus $\sigma$, exceeds a value of $\sigma^{*} / 4=70 \mathrm{MPa}$ because below this value, $\lambda_{\mathrm{f}}$ is nearly constant. In the present case of $\dot{\varepsilon}=2.2 \times 10^{-2} \mathrm{~s}^{-1}$, with increasing $\varepsilon$, the stress $\sigma$ grows continuously, attaining a maximum. It then decreases rapidly, while the fictive stress $\sigma_{\mathrm{f}}$ grows rapidly. When $\sigma$ and $\sigma_{\mathrm{f}}$ intersect, $\sigma_{\mathrm{f}}$ according to eq. (5) decreases and takes a sharp turn, but $\sigma$ continues its descent. The flow stress, $\sigma$, goes through stress-undershoot and then overshoot. It crosses over $\sigma_{\mathrm{f}}$ a number of times and finally attains a steady-state value. Accordingly, the relaxation time, $\lambda_{\mathrm{f}}$, oscillates in the opposite direction to $\sigma_{\mathrm{f}}$.

The model calculation of nonlinear viscoelastic behavior, in particular, the stress growth dependence on strain rates and temperatures, agrees well quantitatively with the experimental results (see Figs. 1 and 5), though the model tends to underestimate the degree of nonlinearity at the commencement of the linear to nonlinear transition. The model reveals that
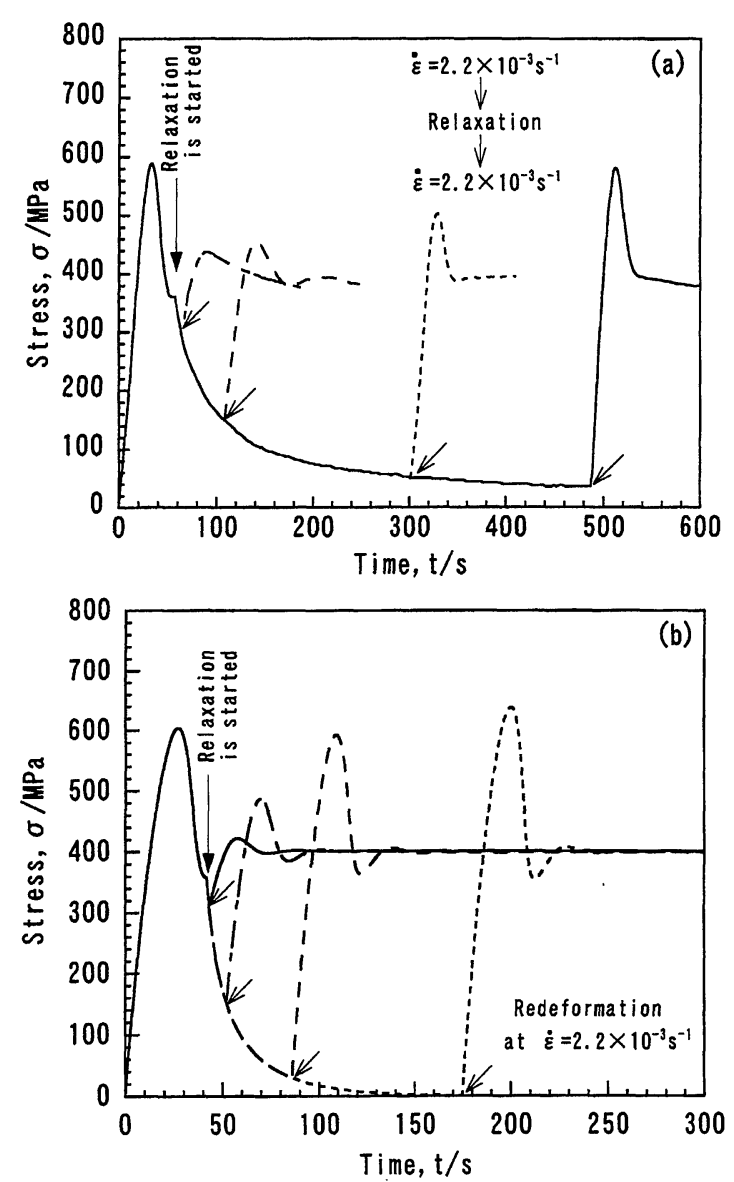

Fig. 12 The experimental (a) and model calculation (b) of a stress regrowth after abrupt cessation of steady-state flow.

the peak position of the stress-overshoot appears at around $\varepsilon=3 \times 10^{-2}$ and shifts slightly with strain rate, $\dot{\varepsilon}$, to higher $\varepsilon$, however the experimental data show all the peak positions occurring near $\varepsilon=5 \times 10^{-2}$. The shift in the peak position of the overshoot with $\dot{\varepsilon}$, is consistent with that observed in polymer glasses. ${ }^{20)}$ The model calculation reveals the stress-overshootundershoot oscillatory behavior which has been observed in many polymer solutions and in metallic glasses.

In the following, we perform viscoelastic deformations of complex step tests with the model and investigate structure change during deformations. ${ }^{21)}$ In this study, a multicomponent $\mathrm{Zr}_{55} \mathrm{Al}_{10} \mathrm{Ni}_{5} \mathrm{Cu}_{30}$ glass alloy $\left(T_{\mathrm{g}}=680 \mathrm{~K}\right.$ at a heating rate of $0.33 \mathrm{~K} / \mathrm{s}$ ) was chosen for the experimental test because of its high thermal stability. The dependence of $\lambda_{\mathrm{f}} / \lambda_{\mathrm{N}}$ and $\sigma_{\mathrm{f}} / \sigma^{*}$ on $\dot{\varepsilon}$ at various temperatures can be expressed in a stretched exponential relaxation form, eq. (3) with $\beta=0.96$ (Fig. 9(b)).

As in the case of the Pd-based alloy glass, model calculations are made using eqs. (4), (5) and (6) for $\mathrm{Zr}_{55} \mathrm{Al}_{10} \mathrm{Ni}_{5} \mathrm{Cu}_{30}$ glassy alloy at $T=670 \mathrm{~K}$. In the calculations, $E$ and $\lambda_{\mathrm{N}}$ are $20 \mathrm{GPa}$ and $26 \mathrm{~s}$ respectively, ${ }^{22)}$ according to the experimental results. The stretched exponent $\beta=0.96$ is determined for the Zr-based alloy glass. Figures 12(a) and (b) show the experimental data and model calculations of the $\mathrm{Zr}$-based glass subjected to an initial deformation of the nonlinear viscoelastic regime at $\dot{\varepsilon}=2.2 \times 10^{-3} \mathrm{~s}^{-1}$ until $\sigma$ attains a steady-state value, then stress relaxed at the static strain for various time. It was followed by redeformation at the same strain rate. As 

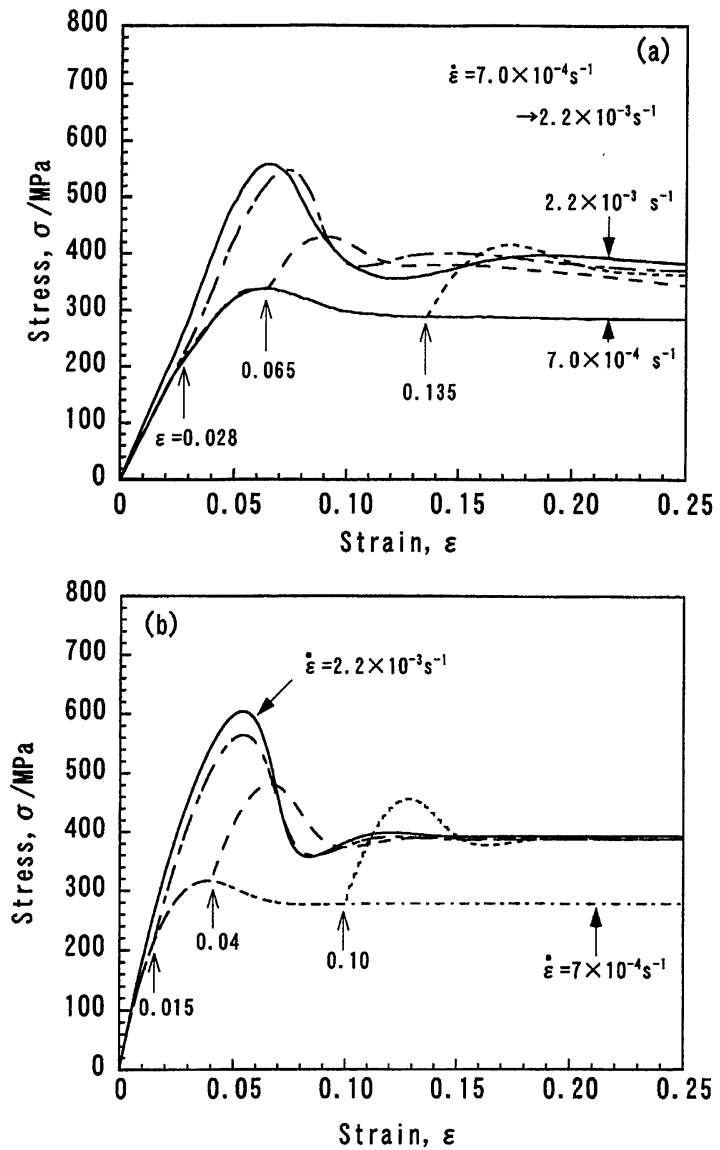

Fig. 13 The experimental (a) and model calculation of stress growth of sudden switch of $\dot{\varepsilon}$ from $7.0 \times 10^{-4} \mathrm{~s}^{-1}$ to $2.2 \times 10^{-3} \mathrm{~s}^{-1}$ at various $\varepsilon$.

seen in Figs. 12(a) and (b), the longer is the time for a static stress relaxation, the larger is the stress growth of a stress overshoot. The stress growth of the most relaxed sample is nearly the same as that of the starting sample. In contrast with this behavior, the steady-state flow stress is independent of time for the static stress relaxation, i.e., $\sigma_{\mathrm{f}} \sim 380 \mathrm{MPa}$. The curves calculated with this model agree well qualitatively as well as quantitatively. It should be noted that these curves exhibit a large stress overshoot which is followed by a stress undershoot and then exhibit oscillatory behavior in the $S-S$ curves. During the static stress relaxation, both $\sigma$ and $\sigma_{\text {fic }}$ decrease and deviate from the steady-state flow stress, $\sigma_{\mathrm{f}} \sim 380 \mathrm{MPa}$. The degree of structural relaxation indicated by $\sigma_{\text {fic }}$ depends on the duration of the static state. After a sufficiently long waiting time $\gg \lambda_{\mathrm{N}}$, the structure returns to a static equilibrium (linear) state at $T=670 \mathrm{~K}$. Following constant strain-rate deformation, a stress overshoot appears again. The stress growth depends on the degree of structural recovery to the static equilibrium state during the static stress relaxation. A well-relaxed structure, as indicated by $\sigma_{\text {fic }} \rightarrow 0$, must change significantly to reach the steady-state flow structure. As a result, the stress growth becomes large. The relaxation time of the static stress relaxation is underestimated because $\lambda_{\mathrm{f}}$ may be different from $\lambda_{\mathrm{sr}}$ under a static condition.

Figures 13(a) and (b) show respectively the experimental and model S-S curves for the $\mathrm{Zr}$-based glass subjected to deformation at $\dot{\varepsilon}=7 \times 10^{-4} \mathrm{~s}^{-1}$ up to various strains, then the $\dot{\varepsilon}$ is switched to a higher value of $2.2 \times 10^{-3} \mathrm{~s}^{-1}$. As shown

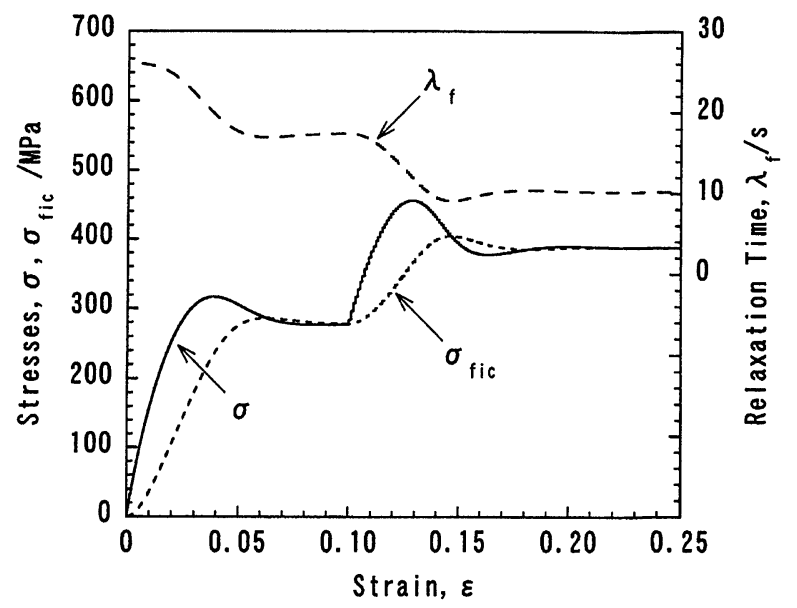

Fig. 14 The relationship among $\sigma, \sigma_{\mathrm{f}}$ and $\lambda_{\mathrm{f}}$. Strains at which the strain rate is switched from $7.0 \times 10^{-4} \mathrm{~s}^{-1}$ to $2.2 \times 10^{-3} \mathrm{~s}^{-1}$ are indicated by arrows in the figure.

in Figs. 13(a) and (b), the smaller is the strain at which the strain rate switches from $7.0 \times 10^{-4} \mathrm{~s}^{-1}$ to $2.2 \times 10^{-3} \mathrm{~s}^{-1}$, the larger is the stress growth of the stress-overshoot phenomenon. In all cases, the steady-state flow stress of each curve merges to $\sim 380 \mathrm{MPa}$. These behaviors performed in accordance with the model are shown in Fig. 13(b), and the structure change expressed with the fictive stress and the relaxation time related to the stress during the test, e.g., the switch from $\dot{\varepsilon}=7.0 \times 10^{-4} \mathrm{~s}^{-1}$ to $2.2 \times 10^{-3} \mathrm{~s}^{-1}$ at $\varepsilon=0.10$, are shown in Fig. 14. The stress growth of the stress overshoot depends on the value of $\sigma_{\text {fic }}$ at which the strain rate switches from $7.0 \times 10^{-4} \mathrm{~s}^{-1}$ to $2.2 \times 10^{-3} \mathrm{~s}^{-1}$ and $\sigma_{\mathrm{f}}$. The smaller the $\sigma_{\text {fic }}$ at the time of the switch, the larger the stress overshoot.

\section{Conclusion}

The deformation of glassy alloys around $T_{\mathrm{g}}$ is viscoelastic basically depending on both temperature and strain rate. The steady-state flow is divided into two modes, a linearmode of Newtonian and a nonlinear mode of non-Newtonian. At higher strain-rates where flow stresses approach the maximum stress, the slope of viscosity versus strain rate in the nonlinear regime is approximated to -1 , which indicates that the distribution of relaxation time is quite narrow because of its simple atomic structure. Hence the relation between the viscosity and the strain rate can be fitted with stretched exponent, $\beta$ approaches 0.96 , relaxation function on the basis of a simple relaxation- function.

The stress-induced structural relaxation is thought to be the cause of transition between the linear and the nonlinear viscoelasticity. Accordingly we propose a model based on a concept of the fictive stress. The calculated S-S curvesagree fairly well with the experimental results. Furthermore, an oscillation behavior appears in the calculated S-S curves at sufficiently high strain-rates, which has been observed in the recent experimental results of the $\mathrm{Zr}$-based glassy alloy. It is noteworthy that the occurrence of nonlinear viscoelastic phenomenon is determined explicitly by the cohesive strength of a liquid, $\sigma^{*}$, and the product, $\lambda_{N} \dot{\varepsilon}$. In metallic glasses, the transition from Newtonian to non-Newtonian and stress- 
overshoot phenomenon occur for $\sigma$ and $\sigma_{\mathrm{f}} \geq \sigma^{*} / 4$ being about $2 \times 10^{-3} E$. The concept of a fictive stress and the hypothesis of stress-induced structural relaxation appear to be valid, at least they are not in conflict with the experimental data. These viewpoints deserve further investigations and confirmation.

\section{REFERENCES}

1) H. S. Chen: Rep. Prog. Phys. 43 (1980) 353-432.

2) T. Zhang, A. Inoue and T. Masumoto: Mater. Trans., JIM 32 (1991) 1005-1010.

3) H. S. Chen and D. Turnbull: J. Chem. Phys. 48 (1968) 2560-2571.

4) H. S. Chen and M. Goldstein: J. Appl. Phys. 43 (1972) 1642-1648.

5) E. Bakke, R. Bucsh and W. L. Johnson: Appl. Phys. Lett. 67 (1995) 3260-3262.

6) C. A. Volkert and F. Spaepen: Mater. Sci. Eng. 97 (1988) 449-452.

7) S. K. Lee, K. H. Tsang and H. W. Kei: J. Appl. Phys. 70 (1991) $4842-$ 4845.

8) H. S. Chen: J. Non-cryst. Solids 27 (1978) 257-263.

9) H. Kato, Y. Kawamura, A. Inoue and H. S. Chen: Appl. Phys. Lett. 73
(1998) 3665-3667; ibid. Mater. Trans., JIM 41 (2000) 1202-1207.

10) H. S. Chen, H. Kato and A. Inoue: Jpn. J. Appl. Phys. 39 (2000) 18081811.

11) J. D. Ferry: Viscoelastic properties of Polymers, (John Wiley and Sons, New York, 1970).

12) J. H. Simmons, R. H. Mohr and C. J. Montrose: J. Appl. Phys. 53 (1982) 4075-4080.

13) W. W. Graessley: J. Chem. Phys. 47 (1967) 1942-1953.

14) D. M. Heyes, J. J. Kim, C. J. Montrose and T. A. Litovitz: J. Chem. Phys. 73 (1980) 3987-3996.

15) L. J. Zapas and J. C. Phillips: J. Rheol. 25 (1981) 405-420.

16) P. J. Carreau: Trans. Soc. Rheol. 16 (1972) 99-127.

17) Y. Kawamura, T. Shibata, A. Inoue and T. Masumoto: Appl. Phys. Lett. 69 (1996) 1208-1210.

18) T. G. Nieh, T. Mukai, C. T. Liu and J. Wadsworth: Scripta Mater. 40 (1999) 1021-1027.

19) F. Bueche: J. Chem. Phys. 48 (1968) 4781-4784.

20) S. Matsuoka: Relaxation Phenomena in Polumers, (Hansa. Publ., New York, 1992) 115-119.

21) H. Kato, Y. Kawamura, H. S. Chen and A. Inoue: Jpn. J. Appl. Phys. 39 (2000) 5184-5187.

22) H. Kato: Ph.D. Thesis, Tohoku Univ. (1999). 